\title{
Panorama da cidade de Manaus: crise, progresso e cultura na década de 1960
}

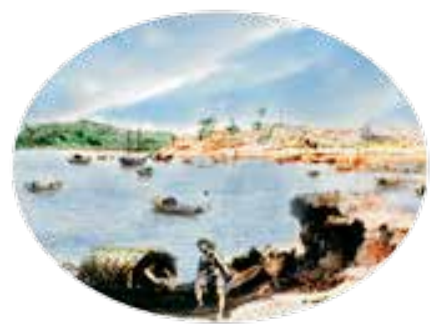

Lucyanne de Melo Afonso*

\section{Resumo}

Este artigo apresenta um panorama da cidade de Manaus na década de 1960. Uma cidade que estava em crise econômica deixada pela borracha e foi melhorando sua situação a partir de projetos de modernização como a Zona Franca de Manaus e a abertura de estradas, favorecendo o crescimento econômico e cultural.

Palavras-chave: Manaus; cidade, panorama; década de 1960.

\begin{abstract}
This article presents a panorama of the city of Manaus in the decade of 1960. A city that was in economical crisis left by the eraser and it went improving its situation starting from modernization projects as the Zona Franca of Manaus and the opening of highways, favoring the economical and cultural growth.
\end{abstract}

Keywords: Manaus; city; panorama; decade of 1960.

\footnotetext{
* Aluna do curso de mestrado do Programa de Pós-Graduação Sociedade e Cultura na Amazônia (PPGSCA) da Universidade Federal do Amazonas (Ufam). E-mail: lucyanneafonso@hotmail.com
} 


\section{Manaus: uma cidade pobre e abandonada}

A década de 1960 marcou um desenvolvimento socioeconômico no Amazonas, como por exemplo, a vinda da Petrobras para perfurar os poços na área do Careiro, Maués e Manacapuru, como relata a reportagem do O Jornal, datado de 27 de março de 1962:

Nessa mesma região já estamos com o poço AM-13-AM, que está atingindo cerca de 1.700 metros de profundidade, $\mathrm{o}$ que bem demonstra o interesse da "Petrobrás" em elucidar o petróleo do Careiro que, não resta dúvida, abriu novas esperanças na pesquisa do ouro negro na Amazônia.

No final dos anos 50 e início dos anos 60 , a cidade de Manaus ficou conhecida como uma cidade precária, abandonada e de economia mal aproveitada que vinha desde a crise deixada pelo ciclo da borracha e que buscava alternativas do mesmo formato econômico da borracha com a exportação de matérias-primas para retornar ao foco do mercado mundial, como bem cita o jornal "Diário da Tarde", de 16 de junho de 1964, divulgando que a Amazônia tem plano de industrialização.

Até agora a área se mantém economicamente mal aproveitada, entre outras razões pela carência de capitais locais, isolomento do resto do país, a que sempre esteve submetida a escassez de energia elétrica. Sem falar no obstáculo representado pela mata espessa.

"Uma Manaus pobre e abandonada": era assim que os jornais da década de 1960 intitulavam suas notícias sobre esta cidade que passou quatro décadas em crise econômica após um período farto, rico e pomposo do ciclo da borracha que se estabeleceu até meados da década de 1920.

Nesta década de 60, a cidade passou por mudanças administrativas, conflitos e discussões sobre a internacionalização da Amazônia; focou não mais em matéria-prima para exportação, mas apostou na industrialização como uma política de integração ao resto do País; e ao crescimento e desenvolvimento econômico com o advento de projetos para integração e consciência nacional de valorização da região. 
É necessário entender como a cidade se comportou nesta fase e, para isso elaborou-se um parâmetro socioeconômico e cultural da cidade de Manaus na década de 1960.

Quando Manaus perdeu o monopólio de produção da borracha para o oriente, que até a década de 1920 era o grande centro de exportação desta matériaprima, houve um grande impacto nas formas de vida na cidade.

Desse período até a década de 1960, de acordo com Oliveira (2003, p.18) é o período conhecido como "período da cidade em crise".

O espaço social vai se modificando e as relações sociais também não são mais as mesmas, principalmente porque inicia aos poucos, uma modificação aos poucos na cultura com a mudança de hábitos e costumes que foram sendo transformados com o estabelecimento de outro padrão social.

Assim, em razão disso, como relata Oliveira (Idem) as festas e as criações artísticas vão dando lugar à vivência urbana, aparecendo como uma alternativa para suprimir as carências sociais. Podemos citar algumas atividades artísticas que surgiram na década de 1960, como por exemplo, os Festivais Folclóricos, os Festivais de Música Popular, a Festa do Violão, os Festivais de Dublagem, o Clube da Madrugada, os programas de Rádio, as festas nos clubes da cidade, enfim, atividades artísticas e culturais da década de 1960 que foram definindo os espaços culturais na cidade.

Manaus era uma cidade pouco desenvolvida após a queda da borracha, ou seja, sua economia estagnou-se, desacelerando sua expansão e seu desenvolvimento como potência da Federação.

Uma questão bastante enfatizada naquela década como motivo de pouco desenvolvimento e uma das consequências desse estacionamento econômico foi o isolamento em função de sua confinação geográfica dos grandes centros de industrialização.

Entretanto, o objetivo da Federação era levar o progresso a estes Estados mais distantes entre eles, Amazonas e Pará, ou seja, a interligação dos Estados da Federação, principalmente os Estados situados na região amazônica pela sua precariedade e distância dos centros econômicos do País, à capital brasileira Brasilia, que era a política do presidente Juscelino Kubitschek, vindo a solucionar problemas na região, mas o Amazonas não foi contemplado, e somente o Pará foi o grande beneficiado.

O deputado Pereira da Silva, autor do trabalho que traçou o roteiro da rodovia em 1956 e apresentou o projeto de lei para ligação imediata da Rodovia 
Transbrasiliana, relatou em entrevista ao jornal impresso O Jornal em 26 de fevereiro de 1960 sua indignação pela não autorização da construção por motivos políticos:

Achavam que a rodovia partindo do centro geográfico da região, colocado mais ou menos no meridional de Manaus, não alcançaria Brasília em tempo anterior à sua instalação oficial como nova Capital da República. Até ai tudo certo, considerada a brutalidade da floresta amazônica e as dificuldades em levar até o eixo do traçado a maquinaria pesada e o material humano necessário a enfrentar a obra, sem dúvida ciclópida. Deixou-se o traçado ManausBrasília, simplesmente por isso, acomodando-se a técnica à lei do menor esforço e, ainda, tendo-se em considerações razões políticas respeitáveis senão imperiosas, exigindo a concretização de um sistema inédito de comunicações que convencesse o Brasil do não isolamento de uma nova metrópole federal com os Estados membros da Federação.

A figura a seguir mostra o projeto criado pelo deputado Pereira da Silva da Transbrasiliana.

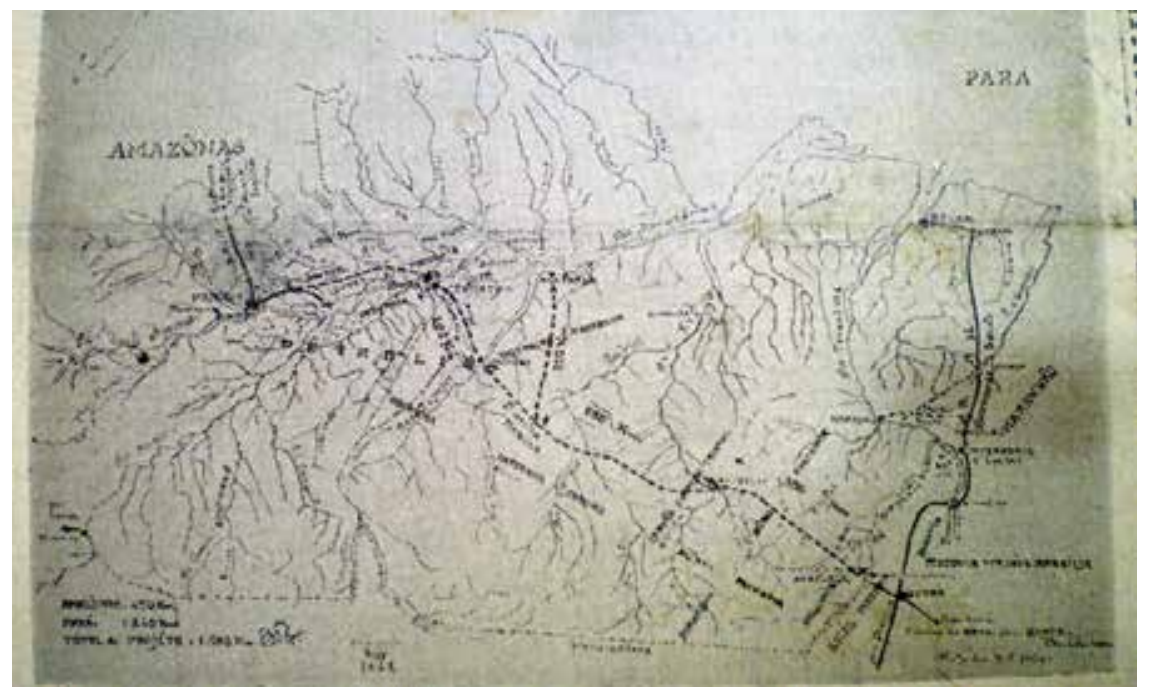

Figura 1 - projeto Transbrasiliana deputado Pereira da Silva, 1956.

Fonte: O Jornal, 26 fev. 1960.

Este é o projeto da estrada Belém-Manaus, de acordo com a proposição Pereira da Silva. 
Isso mostra que a integração dos Estados situados na região amazônica e que, por sua vez, essa integração significava um avanço para a região, já estava sendo discutido desde meados de 1956 e por meras razões políticas não se concretizou em função de um tempo exímio para sua construção devido ao trajeto geográfico ser de difícil acessibilidade, atrasando uma década de desenvolvimento da região.

Manaus buscava alternativas para retornar sua independência financeira e retornar como centro econômico do País como era na época da borracha. Sua maior matéria-prima sempre foi a natureza, procurando fontes para emergir novamente da crise.

"Ferro e aço farão um Amazonas realmente forte", noticiou o jornal A Crítica de 26 de abril de 1961. A criação da Usina Siderúrgica do Amazonas foi o marco aos novos destinos da terra e de seu povo: "como os primeiros frutos de uma indústria que significará mais trabalho e maior desenvolvimento para a região" (idem). Assim como no ciclo da borracha que Manaus exportava a matéria-prima, o ferro e o aço

arrancados do próprio solo e transformados em matériasprimas para todas as necessidades de homem e do meio, será o maior grito de independência econômica dessa região imensa que pouco a pouco vai se projetando no cenário industrial do mundo (Ibidem).

Neste mesmo ano, 1961, a Petrobras inicia sua instalação no Amazonas, especificamente nas regiões do Careiro, fazendo perfurações em busca do ouro negro. No periódico “O Jornal” de 27 de março de 1962 divulgou as notícias dos trabalhos da Petrobras na região: "nesta mesma região, já estamos com o poço AM-013-AM que está atingindo cerca de 1.700 metros de profundidade, o que demonstra o interesse da Petrobras em elucidar o petróleo do Careiro" (O Jornal, 27 de março de 1962).

Isso mostra o quanto Manaus estava em busca de uma independência econômica, mas utilizando o mesmo padrão da época da borracha: "com preços impostos pelos mercados de consumo e, portanto sujeitos a todas as flutuações e exigências que eles cobrem" (REIS, 1966, p. 307). 
Assim foi esse período; algumas empresas começando a investir na região novamente, mas com um mesmo padrão de uma economia extrativista, sujeito a modificações no mercado e podendo falir como foi na época da borracha, deveria ser algo com um maior tempo de duração para estabilizar a economia novamente.

\section{Renascimento da cidade}

A partir de 1964 inicia-se uma nova etapa em Manaus, período que começa com o regime militar e que vai dar nova forma de atividade econômica à cidade.

O Governo Federal passa a oferecer estímulos a empresas nacionais para se instalar nos Estados da Amazônia com isenção de impostos durante cinco anos às indústrias simples e 20 anos às indústrias de transformação.

O Governo Federal oferecia condições atrativas à indústria, no que se referia à madeira, minérios, fibras e borracha, e a agropecuária. No periódico "Diário da Tarde" 16 de junho de 1964 na matéria intitulada Amazônia tem um plano de industrialização faz um registro das condições de desenvolvimento econômico que a região estava propícia.

A região amazônica oferece condições atraentes para a exploração da indústria e da agropecuária, no primeiro caso principalmente nas atividades ligadas à madeira, borracha, fibras, minérios e sementes oleaginosas. São setores que, lá, mais do que em qualquer outra parte do País, podem proporcionar elevados rendimentos e sempre novas possibilidades de expansão.

Enquanto isso, o Governo Federal começava a marcha de conquista da região amazônica, e um dos planos era a ligação Brasília-Manaus, a ser feita no ano seguinte "segundo os estudos prontos" (Jornal do Commercio, 6 de fevereiro de 1964), que já era para ser feita desde 1956, com o projeto do deputado Pereira da Silva.

Essa conquista da região fez com que muitos pudessem verificar a real situação da Amazônia e, assim, fez o jornalista Nelson Moreira que intitulou a Amazônia como abandonada, descrevendo sua viagem: "Do bojo de um avião descerei as profundezas do inferno verde, depois de trinta dias ressuscitarei" 
(Jornal do Commercio, 2 de abril de 1964), mostrando aos outros brasileiros os problemas do Norte e pedindo aos representantes dos diversos legislativos que pudessem tomar providências fazendo com que a região tivesse uma existência digna e que orgulhasse a pátria.

Diante de tantos problemas que a região enfrentava e ocasionava ao governo brasileiro, o Brasil já não tinha condições de sustentar esta imensa região levando a uma discussão sobre a internacionalização da Amazônia, o qual o governador do Amazonas, Arthur Cesar Ferreira Reis, que ficou no mandato de 1964 a 1967, foi o principal questionador, mobilizador e renovador em relação à imagem que o Brasil tinha sobre a região sendo fundamental a sua articulação para o progresso na cidade de Manaus.

\section{O governo militar de Arthur Cesar Ferreira Reis}

O governador Arthur Cesar Ferreira Reis foi o primeiro governo militar na cidade de Manaus. Seu mandato foi de 29 de junho de 1964 a 31 de janeiro de 1967 apontado pelo presidente da República, Castello Branco.

Nesse período aconteceu a fase de mudanças administrativas e culturais na cidade. Seu empenho foi direcionado para as causas da Amazônia e incentivou a publicação de "obras de autores amazonenses, reativando a cultura do Estado e reestruturando entidades da maior importância para a vida social e econômica do Amazonas" (ROCHA, 2011).

Arthur Cesar Ferreira Reis participou ativamente contra o governo na $1^{a}$ ditadura militar na década de 30 , se tornou chefe do gabinete da Junta Revolucionária no Estado, contando com o apoio dos estudantes.

Em seu mandato como governador no Amazonas era conhecido como o "Velho Reis, um intelectual totalmente aberto" (MARINHO, 2011) para o desenvolvimento das artes como "Festival do Cinema, Festival de música, Feira do Livro, isso tudo graças ao Arthur Reis" (MARINHO, 2011); ou conhecido como o "Amigo das Artes" (NOVAL, 2011).

Foi o empenho de Arthur Reis que conseguiu reverter a situação econômica em que Manaus se encontrava e fazer modificações na consciência nacional frente à realidade amazônica.

Em 1965, foi um ano em que Arthur Reis foi o principal personagem que promoveu no Brasil uma discussão a respeito da internacionalização da 
Amazônia, para que o Brasil reconhecesse a Amazônia como pertencente à Federação. Os jornais da época mostravam a movimentação a respeito dessa polêmica entre políticos, economistas, jornalistas, entre outros.

Ao mesmo tempo em que o Governo Federal estava incentivando empresas para investir na região amazônica, como escreveu o colunista Gabriel Hermes para o "Jornal do Commercio", 16 de abril de 1965:

É condição precípua para concretizar a integração da região amazônica na Comunidade Nacional. [...] Agora é o momento de despertar e convocar a compreensão nacional para a necessidade da Integração da Amaz̃onia, como região econômica a ser despertada. [...] É hora de integração da Amazônia e de ocupar em termos econômicos e por brasileiros a imigração selecionada no seu território. É o momento de repelir a condição de colônia interna a que nos temos submetido. Não queremos cobrar do ilustre senhor Castello Branco um discurso sobre a Amazônia, mas interessar o presidente um plano de Desenvolvimento, um novo mecanismo de planejamento, uma nova política do Poder Central na região [grifo do autor].

O Governo Federal estava também percebendo que o Brasil não teria condições de sustentar esta região. Enquanto isso os militares repelem a intervenção. O deputado Wilson Calmon esclareceu que "os militares não concordarão jamais com a intervenção estrangeira na Amazônia, porque a região constitui patrimônio intocável que deve ser explorado unicamente por brasileiros" ("Jornal Meridional" 17 de maio apud "Jornal do Commercio", 18 de maio de 1965).

No Rio de Janeiro, um ministro de Estado disse "que o Brasil não tem condições para assumir a posse efetiva da Amazônia e, como consequência, terá de pedir o concurso dos americanos" ("Jornal do Commercio", 22 de maio de 1965.)

O governador Arthur Reis retrucou contra o ministro de Estado: "Isso - uma verdadeira afronta ao povo e a cultura brasileira que nada mais traduz do que o desprezo dos Estados Unidos por nossos valores culturais e técnicos" (Idem). 
E após todos os conflitos políticos, econômicos e administrativos que permeou sobre a questão, Arthur Reis se dirige a população amazonense através das emissoras da cidade para o pronunciamento de sua mensagem e transcrita no "Jornal do Commercio", 14 de agosto de 1965:

\begin{abstract}
Chegou a hora de dar aos meus conterrâneos, a todos os habitantes do Amazonas, um esclarecimento direto sobre os últimos acontecimentos. [...] Correrá o Brasil um grande risco, o risco mortal de ser a Nação desfigurada de sua fisionomia histórica, desviada do caminho que busca desde que teve autonomia, sujeita a uma dominação estrangeira. [...] Caberá ao povo do Amazonas dar solução a essa pretensão. Mas esse povo o vai fazer em liberdade, e não sob a coação moral e física que anteriormente sofria. Vamos preparar este ambiente para que a liberdade e a Democracia possam vicejar no Amazonas e para que o seu povo tenha, efetivamente, em mãos os seus destinos [...].
\end{abstract}

Arthur Reis encomendou ao poeta e compositor Aureo Nonato, artista de grande prestígio na cidade, uma música para inverter a visão que o Brasil tinha da região, para negar sua doação aos americanos e para incentivar sua gente a partilhar do mesmo sentimento de pertença, de orgulho de sua cidade, para autoafirmar sua origem, suas identidades, visto que Manaus acolheu pessoas de todo o Brasil no período da borracha.

A música intitulada "Canção Manaus" influenciou no seu tempo e no espaço. Seu lançamento no dia 27 de junho de 1965, num domingo, com várias personalidades da política, artística, civis e militares, demonstra a unificação desse orgulho, desse sentimento de pertença que o Governo de Arthur Cesar Ferreira Reis implantou na cidade para apoiar nas suas lutas contra a internacionalização da Amazônia e para mostrar ao Brasil que a Amazônia a pertencia, e que devia se responsabilizar e olhar mais para a região, para seu povo e suas riquezas.

A nota a seguir, do Jornal do Commercio de 29 de junho de 1965, mostra como foi esse dia de grande comemoração da vitória política, exaltação a cidade e às conquistas do governo de Arthur Reis tendo como pano de fundo a música de Aureo Nonato. 


\section{Manaus já tem sua canção}

Obteve o maior êxito, o lançamento da canção "Manaus" de Aureo Nonato, realizado no domingo último, no bairro de São Raimundo, na interpretação do Coral João Gomes Jr. e da banda de Música da Polícia Militar do Estado.

Além da grande massa que se comprimia, na praça fronteira ao Sul América Esporte Clube, estiveram presentes ao ato o deputado Rui Araújo, presidente da Assembleia Legislativa do Estado, que representou o governador Arthur Reis, o deputado José Bernardo Cabral que saudou o compositor Aureo Nonato, em nome do Poder Legislativo, autoridades civis e militares, poetas, jornalistas e elementos da nossa sociedade [grifo nosso].

A partir dessas discussões é que o Brasil iniciou os projetos de desenvolvimento da Amazônia para diminuir as distâncias dos grandes centros econômicos do País: a Zona Franca de Manaus e o projeto da Rodovia Transamazônica, o que viria a integrar a Amazônia ao restante do País.

Contudo, houve uma modificação na consciência nacional sobre esta região, possibilitando que o Brasil legitimasse esta região sendo da Federação, realizando planos para seu desenvolvimento, o que proporcionou o período de integração e ocupação na Amazônia com os projetos do governo de Arthur Cesar Ferreira Reis de efetivar ao presidente da República.

\section{Integração e ocupação de Manaus}

Após um período de discussões sobre a internacionalização da Amazônia em que Arthur Cesar Ferreira Reis foi o principal agente de modificação da consciência política nacional sobre a região, Arthur Cesar relatou: “impõem-se a sua ocupação com a identificação do que é possibilidades e potencial econômico, poder incorporar-se em definitivo com a economia brasileira e mundial. [...] impõem-se urgente uma consciência brasileira em torno à gravidade do problema da Amazônia” (REIS, 1966, p. 307).

Conceitos mitológicos sobre a região prejudicaram sua arrancada para o desenvolvimento econômico, o qual foi um dos responsáveis pelo relativo abandono em que a região se encontrava por parte do Governo Federal.

Nesse momento, a consciência nacional foi despertada e, aos poucos, foi modificando "conceitos tradicionais e negativismos quanto à viabilidade 
econômica de aproveitamento de seus recursos e da sua efetiva integração no todo nacional" (REIS, 1966, p. 308).

Inicia-se então, a partir de 1966, uma nova política de valorização econômica, que já vinha sendo feita desde a década de 50, mas que foi implantada de fato no governo militar.

Em declaração ao "Jornal do Commercio" de 1. ㅇ de abril de 1966, Arthur Cesar Ferreira Reis faz um relatório sobre seus dois anos de mandato:

[...] encontrei um Estado cujos servidores eram pagos a salários de fome. [...] A Reforma Administrativa compõe outro objetivo dos novos tempos de viver. [...] Somos um povo pobre que precisa tomar consciência dessa verdade. Em consequência, os recursos de que dispusermos não poderão ser empregados indisciplinadamente, mas dentro de planos objetivos e exequíveis.

Os planos eram os projetos de modernização que o governador Arthur Reis encaminhou ao presidente da República. Esse plano constou da abertura para a industrialização que compreendia o Projeto Siderúrgico, Projeto Sal, Projeto de Papéis Finos e a Energia Elétrica, citados nos estudos da Codeama para o presidente da República, visando a extirpação dos principais pontos que estrangulavam a economia amazonense impedindo a sua integração à realidade nacional.

Sendo que a pobreza tecnológica era precária, a produção era feita por métodos empíricos e atrasados, e pouco se produzia; apenas para comer e sobreviver: essa era a realidade e para amenizar a situação criou-se a "Operação Amazônica" ("Jornal do Commercio", 4 de dezembro de 1966).

Com isso, máquinas iniciam a derrubadas de árvores pela floresta fechada, tratores são expostos como "Máquinas para o progresso" "“Jornal do Commercio", 3 de julho de 1966) e a Amazônia não deveria continuar sendo somente natureza, pois sua ocupação era responsabilidade dos brasileiros. 


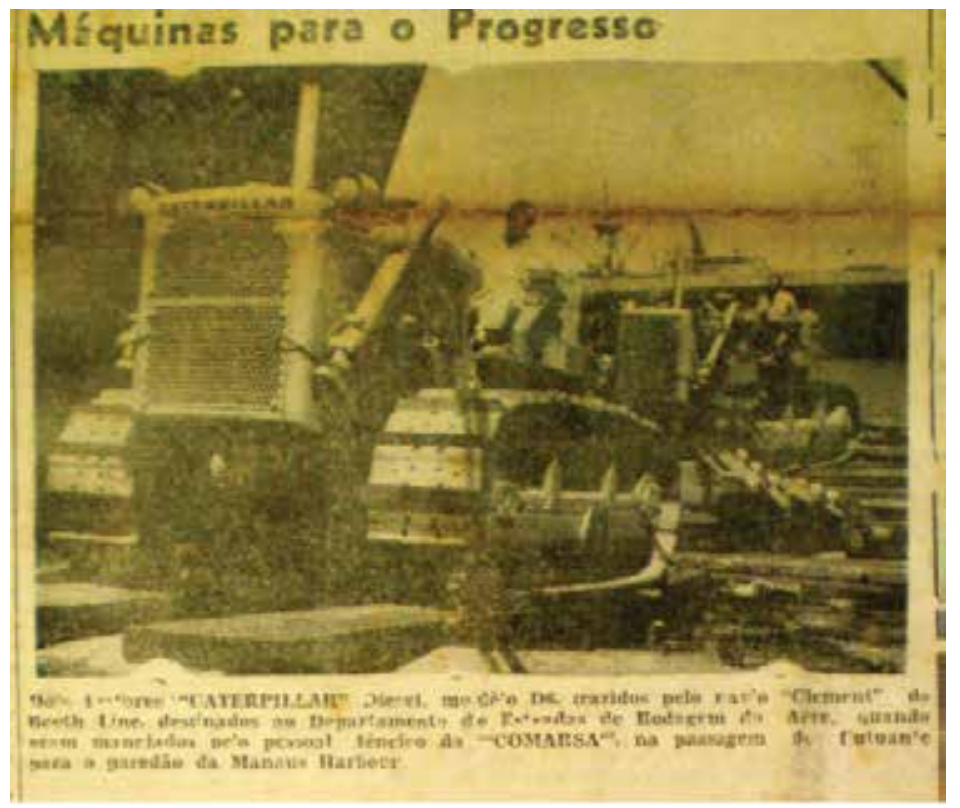

Figura 2 - Máquinas para o progresso.

Fonte: Jornal do Commercio, 3 de jul. 1966.

Dois tratores "Caterpillar" Diesel modelo D6 trazidos pelo navio "Clement" da Booth Line, destinados ao Departamento de Estradas de Rodagem do Acre quando eram manejados pelo pessoal técnico da "Comarsa" na passagem do flutuante para o paredão da Manaus Harbour.

A construção da Rodovia Transamazônica ligando o Norte ao Centro-sul do Brasil e, "principalmente, com a criação, em 1967, por meio do Decreto Lei 288, de 28 de fevereiro de 1967, da Zona Franca de Manaus e a implantação do Distrito Industrial de Manaus, modificaram significativamente a paisagem urbana" (OLIVEIRA, 2003, p. 67). Já não era mais mitologia, mas um projeto de crescimento para a cidade, que foi impulsionado pelo governo militar de Arthur Cesar Ferreira Reis.

Carmine Aronne em nota divulgada no "Jornal do Commercio" de 4 de maio de 1967, descreve como estava sendo vista esta "ocupação da Amazônia":

Estamos assistindo sobretudo a partir da Revolução de 31 de março de 64, um vivo interesse das forças atuantes da Nação em torno da Amazônia, que em boa hora se 
desgarrou do aspecto literário e turístico sob o qual vinha sendo encarada, para entrar de cheio naquela fase que mais nos interessava: a sua reintegração nacional, em bases de economia e desenvolvimento.

A partir de 1967 com o governo de Danilo de Matos Areosa, sucedeu-se a estruturação da Zona Franca, permitindo interesses e progresso pela cidade de Manaus.

Os interesses não eram somente o desenvolvimento da economia local: uma cidade para ter progresso não depende somente gerar fontes de renda: com a instalação da Zona Franca elaborou-se um programa que visasse não somente o desenvolvimento econômico de Manaus, mas também o seu desenvolvimento cultural.

Foi imprescindível para um trabalho de recuperação da cidade, "não havendo trabalho isolado" (Frota, "Jornal do Commercio", 19 de novembro de 1967), ou seja, o turismo e a cultura foram fatores preponderantes para alavancar o desenvolvimento do município.

Ao visitar o Amazonas o excursionista não pensa em visitar obras moderníssimas, nem banquetes em luxuosos palácios. Todavia, em conhecer bem de perto a prodigalidade dessa natureza incomparável, os costumes do nosso povo primitivo, nossa atual civilização (idem).

Frota (Jornal do Commercio, 19 de novembro de 1967) ressalta como se deu o desenvolvimento das cidades europeias a partir do turismo e da cultura.

$\mathrm{Na}$ Europa onde o turismo é organizado calcula-se em bilhões, os dólares deixados anualmente com essa atividade. Em Portugal, o turismo significa assunto importantíssimo do governo, que considera grande fonte de renda para o progresso da nação. [...] Em Roma, são inúmeros os espetáculos sinfônicos que organizam para os turistas.

Mas Manaus vai sendo culturalmente influenciada pelo modelo norteamericano, em função da política de boa vizinhança entre os Estados Unidos e 
os países da América em decorrência da guerra fria, quando a indústria cultural adentrou o País influenciando gostos, costumes e hábitos, principalmente o rádio e o cinema em Manaus. Influenciando o que comer, o que vestir, e o que ouvir como as músicas dos Beatles, Elvis, Roberto Carlos, entre outros, cada cidade recebeu estas influencias de acordo com seu espaço social e cultural.

Manaus começou a ser uma capital mais movimentada, diferente daquela que se apresentava no período de crise, abandonada e morna, e agora transformada em vitrine modificando a paisagem urbana em função da Zona Franca que foi "criada como um instrumento integracionista, num momento de ascendência do comércio internacional, de hegemonia dos Estados Unidos sobre as outras nações capitalistas" (SOUZA, 2010, p. 180).

A Zona Franca favoreceu o aumento da população de Manaus e atraiu centenas de investidores internacionais, marcando uma nova realidade na cidade. A tabela a seguir, mostra a evolução da população do Amazonas, em pesquisa realizada por Vânia Fonseca e Cleusa Maria Correa (s/d), bolsistas do Conselho Nacional de Pesquisas do Instituto Nacional de Pesquisas da Amazônia. O estudo indicou o crescimento populacional vegetativo e em decorrência da migração, apresentando as porcentagens nos anos de 50, 60 e 70, e o crescente aumento gradativo da população de Manaus.

\begin{tabular}{|c|c|c|c|c|c|}
\hline \multicolumn{6}{|c|}{$\begin{array}{c}\text { TABELA VII } \\
\text { Manaus }\end{array}$} \\
\hline & Creseime & a populaçâ $r$ & periodos 1950 & 50 - $1860 / 70$ & \\
\hline \multirow[b]{2}{*}{ Periodo } & \multicolumn{3}{|c|}{ Cxesetmento } & \multirow{2}{*}{$\begin{array}{l}\text { Pereentual do } \\
\text { erescimento } \\
\text { que é devido } \\
\text { A migracaso }\end{array}$} & \multirow[b]{2}{*}{$\begin{array}{c}\text { Tava ipeometrica } \\
\text { anual de } \\
\text { ereseimento }\end{array}$} \\
\hline & Total & $\begin{array}{c}\text { Parcela que é } \\
\text { devida so } \\
\text { ereseimento } \\
\text { vegetativo }\end{array}$ & $\begin{array}{l}\text { Farcela quw } 4 \\
\text { devida } \mathrm{a} \\
\text { migracâo }\end{array}$ & & \\
\hline $1950 / 60$ & $6 a, 24$ & $90, A B$ & 20,38 & 33,83 & 4.83 \\
\hline $1060 / 70$ & 79,71 & 43,54 & 36,17 & 45,38 & 6,03 \\
\hline
\end{tabular}

Figura 3 - Crescimento da população em Manaus

Fonte: Pesquisa INPA

Esta próxima tabela apresenta em números e por sexo nos anos de 50, 60 e 70 . 
TABELA IX

Manaus

Estrutura da populaçăo, em diversas datas

\begin{tabular}{|c|c|c|c|c|c|c|}
\hline \multirow{2}{*}{ Populacto } & \multicolumn{2}{|c|}{1950} & \multicolumn{2}{|c|}{1960} & \multicolumn{2}{|c|}{1970} \\
\hline & Homens & Mulheres & Homens & Mulheres & Homens & Mulheres \\
\hline TOTAL. & 67.841 & 71.779 & 83.036 & 90,667 & 149.847 & 162.313 \\
\hline$\%$ & 48,50 & 51,41 & 47,80 & 52,20 & 48,00 & 52,00 \\
\hline Global & \multicolumn{2}{|c|}{$139.620\left(^{*}\right)$} & \multicolumn{2}{|c|}{173.703} & \multicolumn{2}{|c|}{312.160} \\
\hline
\end{tabular}

(*) Incluidos os distritos te Airáo e Careiro, que só foram desmembrados $\mathrm{cm} 1955$.

Figura 4 - Crescimento da população em Manaus.

Fonte: Pesquisa Inpa.

De acordo com as pesquisadoras, Fonseca e Correa, "o aumento no crescimento migratório parece ser fruto, em grande parte, de uma esvaziamento do interior do Estado" (s/d, p.6).

Márcio Souza (2010, p. 183) retrata como a Zona Franca modificou significativamente a paisagem urbana de Manaus:

Quando as primeiras quinquilharias foram postas à venda nas lojas de Manaus, e os turistas impertinentes e ávidos começaram a flanar por suas ruas, os amazonenses acreditaram que o pesadelo da depressão e do abandono tinha acabado. A Zona Franca, ou sua manifestação externa e superficial, foi saudada com euforia. As ruas do comércio incipiente encheram-se de portinhas abarrotadas de supérfluos e nos supermercados, se o feijão continuava caro pelo menos era possível encontrar um coq-au-vin enlatado ou sopa campbells. A mentalidade da classe média regozijava-se de consumo.

Isso mostra que a partir de 1967, Manaus teve um crescimento econômico e cultural em face de um projeto de desenvolvimento da região visando sua integração e ocupação, visto que foi um momento propício em função de um investimento nacional e internacional o que favoreceu uma demanda maior de 
consumo de produtos importados, transformando-a numa cidade industrializada aos moldes de uma Liverpool.

E um dos principais pontos para favorecer o crescimento econômico foi a valorização da cultura, como Frota expõe no "Jornal do Commercio", do dia 19 de novembro de 1967, sobre a natureza, o folclore e os costumes que o município oferecia e que o turista podia conhecer e apreciar na cidade.

A flora, com a sua famosíssima vitória-régia; a fauna; os deslumbrantes e piscosos rios; nosso folclore riquíssimo, é tudo que satisfaz a curiosidade do turista. [...] Assim teríamos cuidado com o Tarumã, a cachoeirinha do Tarumãzinho, e a famosa Ponta Negra comprada e arrendada, mas transformada em ambiente digno de oferecer ao visitante. Para os passeios aquáticos em que o Encontro das Águas constitui o mais importante. [...] Nas visitas ao Teatro Amazonas, Museu do Índio, Museu Geográfico e Histórico, etc. [...] A exibição de nossos grupos folclóricos, é outra coisa a providenciar. [...] A organização de grupos efetivos para exibições frequentes, é outra providência elementar a ser tomada. [...] Num programa turístico também tomam parte grupos artísticos que fazem a boa música. [...] Com um programa cuidadosamente planejado, o Departamento de Turismo realizará acertadamente as suas atividades.

Toda essa valorização da cultura era para que o turista não viesse somente fazer compras e gastar seu dinheiro em produtos eletroeletrônicos da Zona Franca, como ressalta Frota (Idem) que "o turista busca conhecimentos e deleites ao seu espírito, deixando em troca a sua grande colaboração, para o progresso do nosso Amazonas", mas que também pudesse vislumbrar o produto cultural e consequentemente haveria uma divulgação da cultura local.

\section{Manaus e o progresso}

A prefeitura de Manaus faz a Lei n. 988 de 17 de novembro de 1967, e no Capítulo IX, intitulado "Das Queimadas e dos cortes de árvores e pastagens, no artigo 137, que dispõe: "A prefeitura colabora com o Estado e a União para 
evitar a devastação das florestas e estimular a plantação de árvores" (Jornal do Commercio, 16 de fevereiro de 1968).

Mas, ao contrário do que afirmava este artigo, na prática era diferente. A conquista da modernidade custou a derrubada de muitas árvores centenárias, a invasão a terras indígenas, ou seja, a pacificação dos índios Wamirins e Atroaris para integrá-los, visto que eram os mais temidos da região, para que o projeto de “colonização" fosse obra prioritária no processo de integração.

A partir de 1968, o governo anuncia medidas para a ocupação da região: extensão da Zona Franca para o interior, integração e ocupação do território, prioridade para telecomunicações, rodovias, energia elétrica, água e esgotos, ampliação do porto, pesquisa mineral, aumento da capacidade da refinaria de Manaus, enfim, projetos para acompanhar o progresso que estava em andamento.

A indústria começou a investir na principal matéria-prima: a madeira. Anúncios nos jornais de empresas mostrando as dezenas de árvores, madeiras e matérias-primas entre elas açacu, morototó, marupá, mamorana, samaúma, jacareúba, andiroba, tatapiririca, virola, parapará e iamanê que servem para fabricação de fósforos, móveis etc. como mostra a figura a seguir:

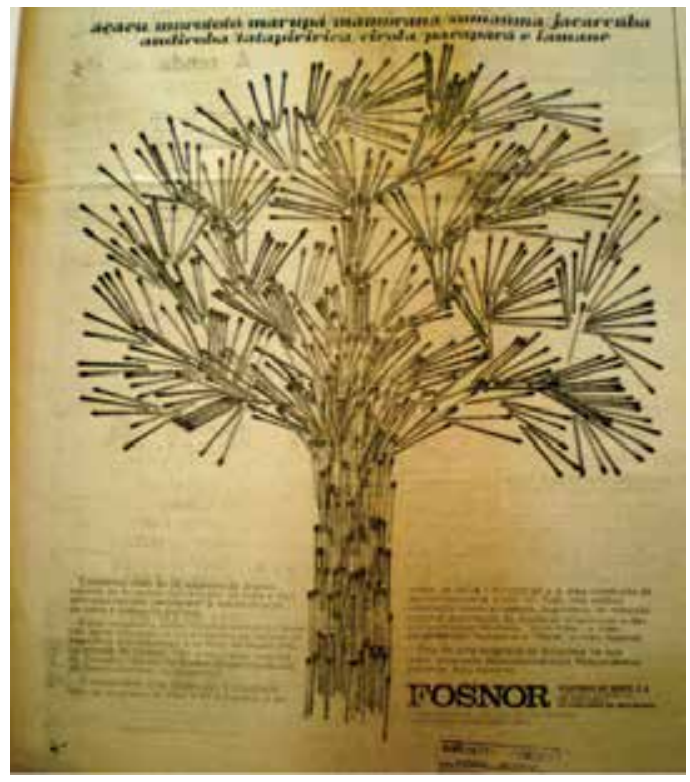

Figura 5 - Nome das árvores que viraram fósforo.

Fonte: Jornal do Commercio, 2 abr. 1968. 
Estudamos mais de 30 espécies de árvores naturais da Amazônia que permitissem a industrialização da caixa e palitos de fósforos. Essas madeiras e outras matériasprimas do Norte são agora utilizadas na nova indústria de fósforos de segurança que erguemos a 14km de Belém (PA) na estrada Icoaraci, com a aprovação unanime do Conselho Técnico da Sudam (Superintedência do Desenvolvimento da Amazônia). [...]

Grandes áreas foram desmatadas para a abertura da Transamazônica e da migração. De acordo com Oliveira (2003, p. 137) esse foi o preço da modernidade que até hoje ainda se encontra incrustada.

Neste sentido, o espaço urbano é um produto histórico e social resultante de um processo de produção e consequência do trabalho humano, pois como sustenta Henri Lefebvre (1986:40), toda sociedade produz seu espaço, ou, se preferirmos, toda sociedade produz um tipo de espaço que garante a sua produção e reprodução.

Um exemplo desse desmatamento foi no trecho Humaitá/Porto Velho com $200 \mathrm{kms}$ de desmatamento, conforme a foto a seguir e o texto especificando os trabalhos de abertura da Transamazônica:

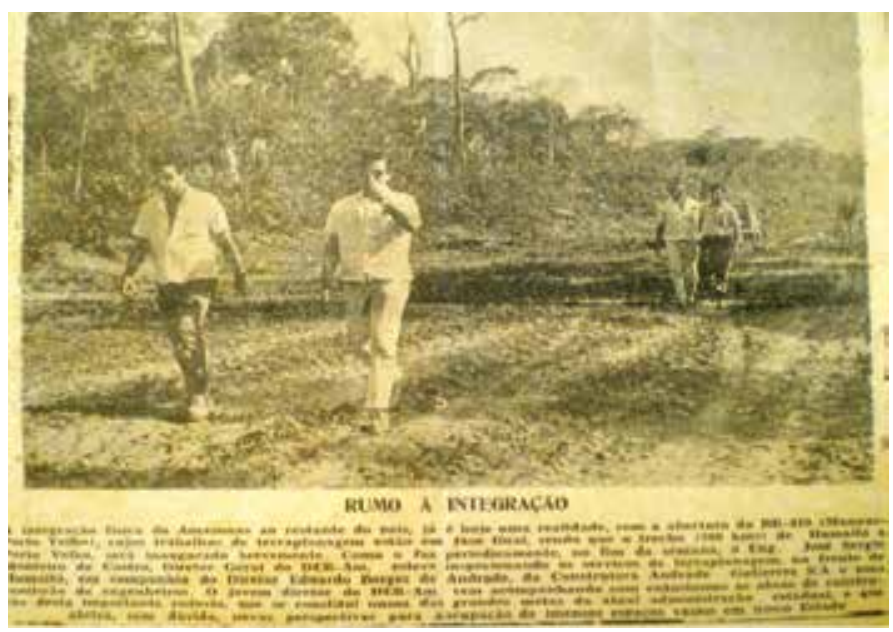

Figura 6 - Rumo à Integração

Fonte: Jornal do Commercio, 7 out. 1969. 


\section{RUMO À INTEGRAÇÃO}

A integração física do Amazonas ao restante do País, já é hoje uma realidade, com a abertura da BR-319 (ManausPorto Velho) cujos trabalhos de terraplanagem estão em fase final, sendo que o trecho $(200 \mathrm{kms})$ de Humaitá a Porto Velho será inagurado brevemente [...] [grigo nosso].

Nesse sentido, a cidade Manaus é resultante de seu próprio processo de construção de uma modernidade. Processo que foi delineado por mudanças de hábitos e costumes, tanto da população que já se encontrava aqui, quanto aos que aqui chegaram pela busca de emprego em se adaptar com o clima, alimentação e qualidade de vida.

O desenvolvimento traz mudanças não só na economia, trazendo mais empregos para a região e sustentabilidade financeira para o Estado, mas influencia todos os campos da vida que serão vivenciados de forma diferente, nos variados padrões de vida que o progresso trouxe, pois quando falamos de progresso, desenvolvimento e integração, junto vem a miséria, a desorganização do espaço urbano e consequentemente doenças provocadas pela falta de saneamento básico e orientação.

O lugar é o mesmo, mas as pessoas aos poucos vão proporcionando a mudança visual desse espaço, assim como o discurso do presidente Costa e Silva à população de Manaus transcrito por Genesino Braga ao Jornal do Commercio no dia 30 de março de 1969:

A bravura da população amazonense que nunca perdera a esperança e jamais se deixara abater pelo pessimismo e o desânimo, apesar da frustração que experimentou com a decadência da borracha que lhe havia dado uma era de esplendor, cujos vestígios ainda são patentes na fisionomia urbana da cidade.

Antes de 1964, uma Manaus pacata e morna pela falta de investimentos, depois de 1966 uma Manaus em transformação e movimentada pelas máquinas das indústrias.

Isso favoreceu, a partir de 1969, a expansão do comércio local e os meios de comunicação ficaram mais viáveis com a chegada de mais emissoras de rádio 
e televisão, além de investimentos em razão do desenvolvimento acelerado, fazendo com que o Governo Federal se empenhasse "em converter a Amazônia no celeiro do Brasil e do mundo" (Jornal do Commercio, idem), dependendo da energia e da perseverança com que o Governo Federal resolvesse concentrar recursos na exploração das riquezas minerais.

A trajetória que Manaus passou nessa década, possibilitou que outros espaços fossem criados, ou seja, não só a economia acelerou e novos rumos foram tomados, mas, em decorrência dessas mudanças, houve também transformações de espaço, de sociedade e de atividades culturais.

O aumento dos meios de comunicação, principalmente das rádios, e no final de década de 60 o surgimento da televisão, possibilitou que a população recebesse mais informações dos acontecimentos do Brasil e do mundo, além da estimulação do setor cultural, promovendo atividades turísticas e culturais na cidade.

Com os projetos de desenvolvimento da economia, como os projetos de industrialização de matéria-prima da natureza, entre outros, trouxeram mais progresso à cidade, favoreceu o aumento da população com a migração, bem como os investimentos no comércio e na indústria e os problemas sociais.

Manaus da década de 1960 foi uma cidade que renasceu da crise da borracha e foi criando uma nova identidade econômica e sociocultural.

\section{Notas}

${ }^{1}$ Manaus - letra e música de Aureo Nonato (1965)

Quem viu você, não pode mais esquecer/ Quem vê você, logo começa a querer Manaus, Manaus, Manaus/Minha cidade querida.

Manaus, Manaus, Manaus, és a cidade sorriso, esperança da nossa Amazônia

\section{Referências}

CODEAMA - Comissão de Desenvolvimento Econômico do Estado do Amazonas. Estudos Específicos. Ano 1, n. 12. Reivindicações. Setor de Publicações. Manaus, dezembro de 1965. 
FONSECA, Vania; CORREA, Cleusa Maria. A evolução da população de Manaus 1950-1970: evolução da população e dos padrões de mortalidade. Pesquisa feita pelo Instituto Nacional de Pesquisas da Amazônia, (s/d).

OLIVEIRA, José Aldemir. Manaus de 1920-1967: a cidade doce e dura em excesso. Manaus: Editora Valer, Governo do Estado do Amazonas, Editora da Universidade Federal do Amazonas, 2003.

SOUZA, Márcio. A Expressão amazonense: do colonialismo ao neocolonialismo. 3. ed. Manaus: Editora Valer, 2010.

REIS, Arthur Cesar Ferreira. A Amazônia e a integridade do Brasil. Série Alberto Torres. Impressos nos Estados Unidos do Brasil. Manaus: Edições Governo do Estado do Amazonas, 1966.

\section{Periódicos}

AMAZONAS Jogado para trás no "rush" rodoviário transbrasiliano: momentosas declarações do deputado Pereira da Silva. O Jornal, Manaus, 26 de fev. 1960.

AMAZÔNIA tem um plano de industrialização. Diário da Tarde, Manaus, 16 de jun. 1964.

ARTHUR: ministro de Castello Branco quer dar Amazônia aos EUA. Jornal do Commercio, Manaus, 22 mai. 1965.

BRAGA, Genesino. A Revolução, o Brasil, o Amazonas. Jornal do Commercio, Manaus, 30 mar. 1969.

FERRO e aço farão um Amazonas realmente forte. Jornal A Crítica, Manaus, 26 de abr. 1961.

FIRME mensagem: Governador dirigiu-se ontem a noite a todo Estado através das emissoras. Jornal do Commercio, Manaus, 14 ago. 1965.

FROTA, Maria Lucia. O turismo e a Zona Franca. Jornal do Commercio, Manaus, 19 nov. 1967.

HERMES, Gabriel. A Integração da Amazônia. Jornal do Commercio, Manaus, 16 abr. 1965.

MANAUS já tem sua canção. Jornal do Commercio, Manaus, 29 jun. 1965.

OPERAÇÃO Amazônica. Jornal do Commercio, Manaus, 4 dez. 1966.

MARCHA o Brasil para a conquista efetiva da região amazônica. Jornal do 
Commercio, Manaus, 2 de fev. 1964.

MOREIRA, Nelson. Amazônia Abandonada. Jornal do Commercio, Manaus, 2 de abr. 1964.

MILITARES repelem a intervenção da Amazônia dizendo-a intocável. Jornal do Commercio, Manaus, 18 mai. 1965.

NOVAS máquinas "Caterpillar" para as rodovias da Amazônia. Jornal do Commercio, Manaus, 3 jul. 1966

PREFEITURA Municipal de Manaus: Lei n. 988 - de 17 de novembro de 1967. Jornal do Commercio, Manaus, 16 fev. 1968.

REIS, Arthur Cesar Ferreira Reis. Ao povo do Amazonas. Jornal do Commercio, Manaus, 1 abr. 1966.

TRABALHOS da Petrobras na Amazônia. O Jornal, Manaus, 27 de mar. 1962.

\section{Entrevistas}

BENAION, Noval. Música popular em Manaus. Manaus, UFAM, 14 jul. 2011. Registro sobre o cenário musical em Manaus na década de 1960. Entrevista concedida a Lucyanne de Melo Afonso.

MARINHO, Joaquim. O rádio e a televisão na difusão da música popular em Manaus. Manaus, UFAM, 6 jul. 2011. Registro sobre os meios de comunicação e o cenário musical em Manaus na década de 1960. Entrevista concedida a Lucyanne de Melo Afonso. 